NBER WORKING PAPER SERIES

\title{
EDUCATION, SEGREGATION AND MARITAL SORTING: THEORY AND AN APPLICATION TO UK DATA
}

\author{
Raquel Fernández \\ Working Paper 8377 \\ http://www.nber.org/papers/w8377 \\ NATIONAL BUREAU OF ECONOMIC RESEARCH \\ 1050 Massachusetts Avenue \\ Cambridge, MA 02138 \\ July 2001
}

I wish to thank Shamika Ravi and especially Jo Blanden for their help with the UK data. I also wish to thank two excellent research assistants - Paolo Dudine and Carlos Maravall - for their timely efforts. Financial support from an NSF grant and the CV Starr center is gratefully acknowledged. I thank the Review of Economic Studies for their invitation to give the RES lecture last year, which led to this paper being written. This paper was prepared for the ISOM conference in June '01. The views expressed herein are those of the author and not necessarily those of the National Bureau of Economic Research.

(C) 2001 by Raquel Fernández. All rights reserved. Short sections of text, not to exceed two paragraphs, may be quoted without explicit permission provided that full credit, including (C) notice, is given to the source. 
Education, Segregation and Marital Sorting:

Theory and an Application to UK Data

Raquel Fernández

NBER Working Paper No. 8377

July 2001

JEL No. I20, J12, D31, E60

\begin{abstract}
This paper presents a model of the intergenerational transmission of education and marital sorting where parents matter both because of their household income and because parental human capital determines the expected value of a child's disutility from making an effort to become skilled. We show that an increase in segregation has potentially ambiguous effects on the fraction of individuals that become skilled in the steady state, and hence on marital sorting, the personal and household income distribution, and welfare. We calibrate the steady-state of our model to UK statistics and compare a version of the model to the results obtained previously for the US. We find that segregation is likely to have a smaller negative impact in the UK than in the US as a result of the fertility and education transmission process. When the relative supply of skilled individuals is endogenous, the welfare effect of increased sorting on unskilled individuals depends on the magnitude of the supply increase.
\end{abstract}

\author{
Raquel Fernández \\ Department of Economics \\ New York University \\ 269 Mercer Street \\ New York, NY 10003 \\ and NBER and CEPR \\ raquel.fernandez@nyu.edu
}




\section{Introduction}

The effect of greater sorting into communities, workplaces, schools and households is becoming a topic of concern in many countries. Wilson (1987) and Reich (1991), for example, have worried that increased segregation at the community level or in the creation of new "gated communities" will lead to increased inequality in the US. In Europe, observers worry that the geographic and social marginalization of recent immigrants may lead to increased social tensions. In the UK, the stratification of the social system and the existence of a self-perpetuating social and educational elite is a perennial topic of debate.

There is some evidence, at least in the US, that there is increased sorting in almost all these spheres. Jargowsky (1996), for example, shows that sorting by income at the neighborhood level appears to have increased across all groups in US metropolitan areas even after controlling for racial and ethnic group characteristics. This appears to be particularly true for Blacks and Hispanics, leading to the fear that lower-income individuals in these groups will be left without positive peer effects provided by a more integrated middle class. Kremer and Maskin (1996) present some evidence that sorting by skill level in the workplace has increased and Mare (1991) shows that the probability that a high school graduate will marry a college graduate has decreased.

This paper is concerned with the effect of increased segregation on marital sorting, inequality and welfare. We present a model of marital sorting in which both environment (the degree of segregation) and preferences (the tradeoff individuals make between the quality of a match and the consumption they would enjoy) determine the degree of assortative matching. In the model, individuals are either skilled or unskilled (according to education decisions made when young) and have a given number of opportunities in which to form a household with another agent. The probability of an individual meeting a skilled or an unskilled individual depends on the degree of segregation in society. Whether a household is formed or not depends on an individual's future matching opportunities, on the quality of the match, and on the household income an individual would enjoy. Couples have children and these in turn decide whether to become skilled or unskilled workers. A decision to become skilled (synonymous here for acquiring a given level of education) is costly, both in terms of resources and in terms of effort. To finance education, young individuals borrow in an imperfect capital market in which parental income plays the role of collateral. Thus parental income and the child's effort cost (the distribution of which is allowed to differ by 
family type), determine the proportion of children from each family type that in aggregate become skilled. These individuals then also meet and form households, have children, and so on.

We show that the steady state to which this economy converges will in general depend upon initial conditions. In particular, it is possible to have steady states with a high degree of sorting (skilled agents form households predominantly with others who are skilled; unskilled form households predominantly with unskilled) and high inequality Alternatively, there can be steady states with a low degree of sorting and low inequality.

We then examine the theoretical effects of an increase in segregation on the steady-state of the economy. We show that this depends not only on the profile of fertility and the propensity for children to become skilled (as in Fernández and Rogerson (forthcoming)), but also on the degree to which this increase in segregation affects the expected utility differential between skilled and unskilled individuals and how this translates into a change in the relative supply of skilled individuals.

Next we examine the effects of an increase in segregation by parameterizing the steady state of the model to several key UK statistics. We use primarily the British Cohort Study to create a sample of parents and children that permits us to examine the degree of correlation of parents in education and the probability that a child from different parental types will become skilled. This, along with data on fertility by parental type, the skill premium, and the elasticity of substitution in production, allows us to find the steady-state proportion of skilled individuals in the economy. We next proceed to examine the effects of an increase in segregation first in a model in which all behavior (i.e., matching and the skill supply by each family type) is exogenously specified. This allows us to compare our results with those of Fernández and Rogerson for the US. We then add endogenous matching to the parameterized model and lastly we allow for endogenous relative supply of factors as well. We find that the effects of increased segregation depends on the specification of the model. Skilled workers are always made better off; the fate of unskilled workers depends on the size of the supply response. In all cases, however, an increase in segregation leads to increased inequality of expected utility between skilled and unskilled workers. From an ex ante utility point of view, however, we find that increased segregation increases welfare in the fully endogenous calibrated model.

The literature most closely related to this paper is Kremer (1997), Fernández and Rogerson (forthcoming), and Fernández, Guner and Knowles (2001). The 
first two papers examine the consequences of greater marital sorting on long-run inequality. Kremer (1997) uses a linear model of intergenerational transmission of education to argue that even a large increase in marital sorting is unlikely to have important quantitative consequences for the distribution of income in the US in the long run. Fernández and Rogerson argue the opposite by showing that the intergenerational transmission process is likely to be non-linear. They show that once fertility differentials and the (non-linear) propensity of children from different family types to become more educated are taken into account, an increase in marital sorting would be likely to have a significant quantitative impact on the US income distribution. Lastly, Fernández et al.(2001) provide a model of marital sorting, fertility and inequality that generates multiple steady states with greater inequality leading to more assortative matching and greater fertility differentials among high and low income families. Using a cross-section of 35 countries, they show that couples are more correlated in their years of education the greater the skill premium and that countries with more sorting have lower per capita income, as predicted by the model. There is also a small literature on endogenous matching but that basically abstracts from the endogeneity of the income distribution in the economy (e.g., Cole, Mailath, and Postlewaite (1992), and Burdett and Coles (1997, 1999)). Aiyagari, Greenwood, and Guner (2000) and Greenwood, Guner and Knowles (200) also examine marriage decisions, but they are primarily concerned with fertility and divorced decisions (which our model does not address) and use a computational approach to solve complicated individual decision problems.

In addition to the literature on marital sorting, there is also a rapidly growing literature that is concerned with various aspects of sorting in other spheres (see Fernández (forthcoming) for a recent review of this literature). Alesina and La Ferrara (2000) examine the consequences of heterogeneity of communities for the formation of social capital. Using survey data on group membership in US localities, they find that participation in social activities is significantly lower in more diverse (racially or ethnically) and more unequal communities. Bisin and Verdier (2000) provide a model of intergenerational transmission of ethnic and religious traits. They find that an increase in segregation increases the fraction of assortative marriages. Fernández and Rogerson (1996) use a multi-community model to show that a local system of financing education is likely to lead to suboptimal sorting of income groups, with too few higher-income individuals living in poorer communities. There is also a large literature that examines the effects of borrowing constraints on human capital accumulation. The most relevant papers 
here are by Benabou (1996), Cooper (1997), Durlauf (1995), and Fernández and Rogerson $(1997,1998)$ as they concerned with the effects of sorting or stratification (into neighborhoods and schools) for the transmission of education and growth in the presence of borrowing constraints.

This paper is organized as follows. The next section sets up the model. Section 3 is devoted to a theoretical analysis of the effects of increased segregation. Section 4 parameterizes the steady state of the model to UK statistics. Section 5 examines the reaction of the parameterized model to an increase in segregation. Section 6 concludes.

\section{The Model}

We consider a two period OLG model with the following timing of decisions. In the first period of life, young individuals decide whether to become one of two types-skilled or unskilled-with each type synonymous with the individual acquiring a given amount of education. Having made the education decision, the individual enters a "household matching market" and acquires a mate. In the second period the individual works, pays off debt associated with the education decision of the first period (if any), consumes and has children.

To simplify our model we take a couple's fertility as exogenous and, as will be seen shortly, we also abstract from bargaining problems within a family by assuming that the couple shares a joint household utility function over consumption. Thus, in the second period of life families simply consume their household income $I$ minus whatever debt repayment they need to make. All the interesting economic action in the model concerns how individuals decide with whom to match given their skill type and how they decide upon a skill type in the first place. We next turn to a discussion of the matching decision.

\subsection{Segregation and Household Matching}

Our model of household sorting (or matching) is simple and yet allows both environment (how segregated schools and neighborhoods are) and preferences (how individuals trade off income and quality of relationship) to matter. Individuals are assumed to have two rounds in which to find a match. The opportunities available in an individual's first round depend on the individual's environment. The opportunities available in the second round depend on the individual's skill type. 
In the first round individuals are more or less segregated according to the individual's exogenously specified environment. There they meet someone and can decide whether to match with that person. If they decide not to match with that person they then enter the second round of matching. In this round, a skilled individual will be matched with another skilled individual, whereas unskilled individuals get matched with other unskilled individuals. This two-step process (as in Fernández, Guner and Knowles (2001)) is meant to reflect that, by and large, when one is younger one has access to a more varied group of individuals (in terms of their final educational attainment) than when one is older. ${ }^{1}$

The role of the environment is reflected in the degree to which individuals are segregated in the first stage. To make this differentiation stark, we assume that a fraction $\theta$ of individuals are perfectly segregated. Within this segment of society, segregation ensures that types do not mix, even when relatively young. Thus, skilled individuals (or individuals who will become skilled) meet only other skilled individuals in the first round; likewise, unskilled meet only other unskilled in the first round. The remaining $1-\theta$ fraction of the population is not segregated. Thus, for the unsegregated portion of the population, if $\lambda$ is the fraction of the population that is skilled, then the probability of a skilled and an unskilled individual "meeting" in the first round is given by $\lambda(1-\lambda)$.

The degree of segregation $\theta$ of the population reflects, among other things, both the residential and schooling environment: e.g., how much society is divided into gated communities, exclusive suburbs, depressed ghettos; the degree of segregation of schools and within a school; the variance of school quality; the prevalence of exclusive private schools and low quality urban public schools; tracking by ability within a school, magnet schools, etc.

We will be interested in examining the consequences to society of an increase in the degree of segregation, $\theta$. Undoubtedly, $\theta$ is itself an endogenous variable, affected by the amount of inequality in society. It is, however, also amenable to public policy. That is, if schools are locally financed (as in the US), there is, for the same amount of inequality, a greater incentive to segregate along income lines into neighborhoods than if schools are centrally funded (as in most European countries) since local financing gives an incentive for higher-income individuals not to mix with lower-income people as different housing values implies redistribution

\footnotetext{
${ }^{1}$ Other matching models are also possible such as random matching over time with discounting. The formulation we have chosen is very tractable and allows us to get rid of the multiple equilibria that can result otherwise.
} 
from those with more expensive property to those with less. ${ }^{2}$ Or, if highways are built allowing easy access from suburbs to jobs in the city, it is easier to segregate into different neighborhoods than in their absence. Alternatively, the placing of some public low-income housing in richer communities or the existence of a lower variance in the quality of schooling may allow a lower degree of segregation for the same degree of inequality. ${ }^{3}$

In order to determine who will match with whom, we need to specify utilities from forming a household. For now, we do not impose any structure other than: (i) Individuals share the same utility from a match. This ensures, for example, that there is no bargaining problem between spouses over the allocation of household income; and (ii) In forming a match, individuals obtain utility both from consumption and from the quality of the match. These two components are assumed to be additively separable. The assumptions above permit us to write the indirect utility from a partner in a match of quality $q$ and household income $I$ as:

$$
V(I, q)=v(I)+q
$$

where $v$ is assumed to be concave.

We assume that quality is perfectly observable to both participants and that it is completely match specific. The draws of quality are independently distributed across rounds and participants. Thus, quality (like beauty, supposedly) is completely in the eye of the beholder, and furthermore is mutual (i.e., the two participants to a match do not disagree about the match quality). Lastly, solely to simplify algebraic presentation, we assume that quality is distributed identically across both types of individuals (skilled and unskilled) so that quality is an iid draw from a cumulative distribution $Q$ in each round of matching.

Note that the assumptions above imply that if two individuals of the same type meet in the first round, either because they belong to the segregated part

${ }^{2}$ See Fernández and Rogerson (1996, 1998) for an analysis of the consequences of a local system of school finance.

${ }^{3}$ The way we have modelled segregation is symmetric for skilled and unskilled inviduals. However, one could well model it as an unsymmetric phenomenon with a fraction $\theta_{s}$ of the skilled population and a potentially different fraction $\theta_{u}$ of the unskilled seceding or being excluded from the rest of the population. This would then imply that the unsegregated part of the population would now consist of a proportion $\frac{\left(1-\theta_{s}\right) \lambda}{\left(1-\theta_{s}\right) \lambda+\left(1-\theta_{u}\right)(1-\lambda)}$ of skilled individuals and a proportion $\frac{\left(1-\theta_{u}\right)(1-\lambda)}{\left(1-\theta_{s}\right) \lambda+\left(1-\theta_{u}\right)(1-\lambda)}$ of unskilled individuals. As we do not have data on the magnitudes of these parameters, we model it as symmetric. 
of society or because they met someone of their own type at random, they will accept any match quality above the mean $\mu=E(q)$ of the quality distribution and reject any that is below. This follows from the fact that their household income is invariant to proceeding to the second round (whereupon they are guaranteed to meet someone of their own type). If, on the other hand, a skilled and unskilled individual meet in the first round (thus, only from the non-segregated part of society), then a skilled individual will only accept the match if $q$ is greater than $q^{*}$, given by:

$$
q^{*}=v\left(I_{s s}\right)-v\left(I_{s u}\right)+\mu
$$

i.e., a quality of match such that a skilled individual is indifferent between obtaining the household income of two skilled individuals, $I_{s s}$, with an expected match quality of $\mu$ and settling for a lower household income of $I_{s u}$.

\subsection{The Labor Market, Family Income, and Sorting}

We next turn to the determination of household income. Given a constant returns to scale production function

$$
F\left(L_{s}, L_{u}\right)=L F(\lambda, 1-\lambda)
$$

where $L_{i}, i \in\{s, u\}$ denotes the amount of labor of type $i$ and $L=L_{s}+L_{u}$, the assumption of a perfectively competitive labor market implies that wages depend only on the fraction $\lambda$ of skilled individuals in the population, i.e.,

$$
w_{s}(\lambda)=F_{1}(\lambda, 1-\lambda) \quad \text { and } \quad w_{u}(\lambda)=F_{2}(\lambda, 1-\lambda)
$$

Most often we will be concerned not with the skilled wage but with its value net of the monetary cost $p$ of acquiring skills, which we denote by $\widetilde{w}_{s}$. Assuming that individuals work only in the second period (whereupon they repay the cost of acquiring skills if they become skilled), and letting $I_{i j}$ denote the household income for a couple composed by skill types $i, j \in\{s, u\}$, we obtain:

$$
I_{i j}(\lambda)= \begin{cases}2 \widetilde{w}_{s}(\lambda), & \text { if } i j=s s \\ \widetilde{w}_{s}(\lambda)+w_{u}(\lambda), \quad \text { if } i j=s u \\ 2 w_{u}(\lambda), \quad \text { if } i j=u u\end{cases}
$$


Thus we can express $q^{*}$ in (2.2) as a function solely of $\lambda$, i.e., $q^{*}(\lambda)$. Note that $q^{*}$ is not a function of $\theta$.

The observations above immediately permits us to solve for the proportion $\varphi$ of each type of household that will form in the population as a function of $\lambda$ and of the population $\theta$ that is segregated.

$$
\varphi_{i j}\left(\lambda_{t}\right)=\left\{\begin{array}{l}
\theta \lambda_{t}+(1-\theta)\left[\lambda_{t}^{2}+\lambda_{t}\left(1-\lambda_{t}\right) Q\left(q^{*}\left(\lambda_{t}\right)\right)\right], \quad \text { if } i j=s s \\
(1-\theta) 2 \lambda_{t}\left(1-\lambda_{t}\right)\left(1-Q\left(q^{*}\left(\lambda_{t}\right)\right), \quad \text { if } i j=s u\right. \\
\theta\left(1-\lambda_{t}\right)+(1-\theta)\left[\left(1-\lambda_{t}\right)^{2}+\lambda_{t}\left(1-\lambda_{t}\right) Q\left(q^{*}\left(\lambda_{t}\right)\right)\right], \quad \text { if } i j=(\longleftrightarrow \mathcal{L} .6)
\end{array}\right.
$$

Remark 1. The degree of correlation of spouses in education (or skill type), $\rho$, is given by $\theta+(1-\theta) Q\left(q^{*}\right)$

It is useful to note the following features of this correlation: (i) it is independent of $\lambda$ except via the endogenous dependence of $q^{*}$ on $\lambda$; (ii) if there is complete segregation $(\theta=1)$, then $\rho=1$; if there is no segregation $(\theta=0)$, then $\rho=$ $Q\left(q^{*}\right)$; (iii) if individuals only cared about household income and not quality then $Q\left(q^{*}\right)=1$ and $\rho=1$; if individuals simply matched with whomever they met in the first round (i.e., $Q\left(q^{*}\right)=0$ ), then the degree of correlation would be governed solely by the degree of segregation of the environment, and hence $\rho=\theta$.

\subsection{The Education Choice}

Next we consider a young individual's decision to become skilled. The expected utility from becoming skilled (gross of any disutility from effort, as will be discussed shortly), given that a fraction $\lambda_{t+1}$ also become skilled, is given by:

$$
\begin{aligned}
V^{s}\left(\lambda_{t+1}\right)= & {\left[\theta+(1-\theta) \lambda_{t+1}\right] \int_{0}^{\bar{q}} \max \left[V_{s s}\left(x, \lambda_{t+1}\right), V_{s s}\left(\mu, \lambda_{t+1}\right)\right] d Q(x) } \\
& +(1-\theta)\left(1-\lambda_{t+1}\right) \int_{0}^{\bar{q}} \max \left[V_{s u}\left(x, \lambda_{t+1}\right), V_{s s}\left(\mu, \lambda_{t+1}\right)\right] d Q(x)
\end{aligned}
$$

whereas the expected utility of becoming an unskilled worker is:

$$
\begin{aligned}
V^{u}\left(\lambda_{t+1}\right)= & (1-\theta) \lambda_{t+1}\left[\int_{0}^{q *} V_{u u}\left(\mu, \lambda_{t+1}\right) d Q(x)+\int_{q *}^{\bar{q}} V_{s u}\left(x, \lambda_{t+1}\right) d Q(x)\right] \\
& +\left[\theta+(1-\theta)\left(1-\lambda_{t+1}\right)\right] \int_{0}^{\bar{q}} \max \left[V_{u u}\left(x, \lambda_{t+1}\right), V_{u u}\left(\mu, \lambda_{t+1}\right)\right] d Q(x)
\end{aligned}
$$


Note that the expected payoff from becoming skilled includes the monetary cost of acquiring an education as skilled wages in both (2.7) and (2.7) are expressed as net of $p$.

Next we turn to the dependence of a child's decisions on her family type. We introduce two different ways in which a family may matter (i) family background; (ii) borrowing constraints. We consider each in turn.

In addition to bearing a monetary cost if they choose to become skilled, individuals also face an idiosyncratic (non-monetary) effort cost $\gamma_{i}$. This magnitude of this cost can be thought of as being influenced by parental background as reflected in the education of these, which can facilitate or make more difficult the child's acquisition of human capital. We allow therefore the distribution of the effort cost to depend on family type and indicate by $G_{i j}(\gamma)$ its cumulative distribution. To simplify exposition, we assume that the draws are perfectly correlated within a family and that $\gamma$ enters linearly in a skilled individual's utility function, i.e., the payoff to individual $i$ of becoming a skilled worker is given by $V_{i}^{s}=V^{s}-\gamma_{i}$.

Define by $\gamma^{*}(\lambda)$ the skilled-unskilled payoff differential generated when a fraction $\lambda$ of the population becomes skilled, i.e.,

$$
\gamma^{*}\left(\lambda_{t+1}\right) \equiv V^{s}\left(\lambda_{t+1}\right)-V^{u}\left(\lambda_{t+1}\right)
$$

Note that an individual with idiosyncratic $\operatorname{cost} \gamma_{i}$ of becoming skilled who expects a fraction $\lambda$ of her cohort to become skilled would also prefer to be skilled as long as $\gamma_{i} \leq \gamma^{*}(\lambda)$.

Next we turn to the effect of parental income on a child's decision to acquire an education. We assume that in order to finance the acquisition of skilled education, children need to access capital markets. ${ }^{4}$ Capital markets are unable to monitor how these funds are spent so that parental income must act as collateral for children. We assume that children within the same family with $n-1$ siblings can borrow up to some (increasing) function $Z(I, n)$ of parental income (e.g., the latter acts as collateral), so that the (integer part) of the solution to:

$$
Z(I, n)=\bar{m} p
$$

yields the maximum number $m_{n i j}=i n t \bar{m}$ of skilled individuals a family with $n$ children and income $I_{i j}$ can produce. Note that $m_{n i j}$ is in general a function of $\lambda$ as this determines family income. For simplicity, we assume that fertility is

\footnotetext{
${ }^{4} \mathrm{~A}$ bequest model would have similar implications.
} 
exogenous, but we allow the number of children $n$ that a family has to depend on family type by modeling it as a random draw from a cumulative distribution $H_{i j}$. We denote by $\eta_{n i j}$ the probability that a family of type $i j$ has $n=\{0,1,2, \ldots, \bar{n}\}$ and use $f_{i j}$ to denote their average fertility, i.e., $f_{i j}=\sum_{n=0}^{\bar{n}} n \eta_{n i j}$.

Putting together both parental income and background, yields

$$
\Gamma_{i j}\left(\lambda_{t}, \lambda_{t+1}\right)=\frac{G_{i j}\left(\gamma^{*}\left(\lambda_{t+1}\right)\right)}{f_{i j}} \sum_{n=0}^{n=\bar{n}} \min \left[m_{n i j}\left(\lambda_{t}\right), n\right] \eta_{n i j}
$$

as the fraction of children that will become skilled given that they belong to families of type $i j$ and that an expected fraction $\lambda_{t+1}$ of that cohort also plans to become skilled.

Note that in the absence of borrowing constraints, $\min \left[m_{n i j}, n\right]=n$ and hence $\Gamma_{i j}=G_{i j}\left(\gamma^{*}\right)$. Furthermore, note that if under this scenario the distribution of non-monetary costs were independent of family background, i.e., $G_{i j}=G \forall i j$, then all families would produce the same fraction of skilled children independent of type. In general, however, $\Gamma_{i j}$ is a function both of $\lambda_{t}$ (since parental income determines the maximum number of children who can afford to become skilled) and of the expected value of $\lambda_{t+1}$ (which given rational expectations must also be the realized value), since this determines the incentive for individuals with different $\gamma_{i}$ to desire to become skilled.

\subsection{Equilibrium}

An equilibrium at time $t$ and $t+1$, for an initial division of the population into skilled and unskilled $\left(\lambda_{t}\right)$, is given by marriage decisions as specified by (2.2), wages as specified by (2.4), and decisions by children to become skilled as specified by (2.10). It is easy to ensure the existence of an interior equilibrium by placing conditions on the production function or on the $Z$ function such that even if $\lambda=0$, some portion of children can afford to become skilled. This ensures that the economy does not get stuck in a poverty trap in which no one can afford to become skilled. To bound $\lambda$ away from one it is sufficient to assume that technology is such that $F_{1}<F_{2}$ for some $\lambda<1$. As shown in the Appendix (to be done), under a mild assumption to ensure that $\gamma^{*}\left(\lambda_{t+1}\right) \equiv V^{s}\left(\lambda_{t+1}\right)-V^{u}\left(\lambda_{t+1}\right)$ is decreasing in $\lambda$, equilibrium will also be unique.

Equilibrium can be depicted as the intersection of two curves as shown in Figure 1. In this figure, the downward sloping curve gives the difference between $V^{s}$ 
and $V^{u}$ as a function of $\lambda_{t}$. The upward sloping line is generated by considering, for a given $\lambda_{t-1}$, the fraction of individuals that both are willing to and can afford to become skilled as a function of $\gamma, \lambda_{t}=\frac{\sum_{i j} \varphi_{i j}\left(\lambda_{t-1}\right) \Gamma_{i j}\left(\gamma, \lambda_{t-1}\right) f_{i j}}{\sum_{i j} \varphi_{i j}\left(\lambda_{t-1}\right) f_{i j}}$. From this relationship we can solve for $\gamma$ as a function of $\left(\lambda_{t-1}, \lambda_{t}\right)$ which we denote by $\Psi\left(\lambda_{t-1}, \lambda_{t}\right)$. This curve is upward sloping since an increase in $\gamma$ will increase the supply of skilled labor from all family types.

\subsection{Dynamics}

We now turn to specifying the dynamic evolution of this economy. The working population in the economy in period $t+1$ as a function of $\lambda_{t}$ is given by:

$$
L_{t+1}\left(\lambda_{t}\right)=\sum_{i j} \varphi_{i j}\left(\lambda_{t}\right) f_{i j} L_{t}
$$

and the number of skilled individuals is:

$$
L_{s, t+1}\left(\lambda_{t}, \lambda_{t+1}\right)=\sum_{i j} \varphi_{i j}\left(\lambda_{t}\right) \Gamma_{i j}\left(\lambda_{t}, \lambda_{t+1}\right) f_{i j} L_{t}
$$

A steady state in this economy will be a skilled fraction of the population $\lambda^{*}$ such that

$$
\lambda_{t+1}\left(\lambda^{*}\right)=\frac{L_{s, t+1}\left(\lambda^{*}, \lambda_{t+1}\right)}{L_{t+1}\left(\lambda^{*}\right)}=\lambda^{*}
$$

Alternatively, we can express the steady state as:

$$
\lambda_{t+1}\left(\lambda^{*}\right)=\frac{\sum_{i j} \varphi_{i j}\left(\lambda^{*}\right) \Gamma_{i j}\left(\lambda_{t+1}, \lambda^{*}\right) f_{i j}}{\sum_{i j} \varphi_{i j}\left(\lambda^{*}\right) f_{i j}}=\lambda^{*}
$$

In general this model may have multiple steady states as the initial condition of the economy may determine which steady state it converges to. This is due to a non-convexity in the form of a discrete amount needed to become skilled and to the presence of borrowing constraints. For example, for a given degree of segregation, an economy that starts out with a low fraction of skilled individuals and thus high inequality between skilled and unskilled, may end up in a steady 
state that reproduces those features due to the fact that uu type families will have low income and are more likely to be constrained. On the other hand, an economy with the same degree of segregation but with a large fraction of skilled individuals will have low inequality and low sorting and can end up in a steady state with a high fraction of skilled individuals as $u u$ family income will be higher and thus they are less likely to be constrained.

In any case, the potential multiplicity of steady states is not the feature of the analysis we wish to emphasize. Our calibration procedure will select a steady state and we will be interested in the effect of a change in segregation we will be given that initial steady state. We now turn to an analysis of this.

\section{The Effect of an Increase in Segregation}

The effect of an increase in segregation in this model depends on: (i) whether the number of children that become skilled next period's skilled is a concave or convex function of parental human capital; (ii) whether the growth rate of fertility is concave or convex in parental types; (iii) the effect of an increase in segregation on the expected utility differential of skilled relative to unskilled individuals.

This can be seen most clearly by totally differentiating (2.14) with respect to $\theta$ and evaluating it at $\lambda_{t}=\lambda_{t+1}=\lambda^{*}$. Doing this yields:

$$
\begin{aligned}
\frac{d \lambda^{*}}{d \theta}= & \frac{\lambda^{*}\left(1-\lambda^{*}\right)\left(1-Q\left(q^{*}\right)\right)\left[\left(f_{s s} \Gamma_{s s}-2 f_{s u} \Gamma_{s u}+f_{u u} \Gamma_{u u}\right)-\lambda^{*}\left(f_{s s}-2 f_{s u}+f_{u u}\right)\right]}{D} \\
& +\frac{\sum_{i j} \varphi_{i j}\left(\lambda^{*}\right) f_{i j} \frac{\Gamma_{i j}\left(\lambda^{*} ; \theta\right)}{G_{i j}\left(\lambda^{*} ; \theta\right)} \frac{\partial G_{i j}\left(\gamma^{*}\left(\lambda^{*} ; \theta\right)\right)}{\partial \gamma^{*}} \frac{\partial \gamma^{*}}{\partial \theta}}{D}
\end{aligned}
$$

where

$$
\begin{aligned}
D= & \sum_{i j} f_{i j} \varphi_{i j}\left(\lambda^{*} ; \theta\right)+\sum_{i j} f_{i j} \frac{\partial \phi_{i j}\left(\lambda^{*} ; \theta\right)}{\partial \lambda}\left(\lambda^{*}-\Gamma_{i j}\right)- \\
& \frac{\partial \gamma^{*}}{\partial \lambda}\left(\sum_{i j} \varphi_{i j}\left(\lambda^{*}\right) f_{i j} \frac{\Gamma_{i j}\left(\lambda^{*} ; \theta\right)}{G_{i j}\left(\lambda^{*} ; \theta\right)} \frac{\partial G_{i j}\left(\gamma^{*}\left(\lambda^{*} ; \theta\right)\right)}{\partial \gamma^{*}}\right)
\end{aligned}
$$

is required to be positive in order for the original steady-state to be locally stable. ${ }^{5}$

${ }^{5}$ Note that $\frac{\partial \phi_{i j}\left(\lambda^{*} ; \theta\right)}{\partial \lambda}$ has two components: one is what happens to the proportion of couples of different types due to the change in $\lambda$; the other is what happens to these proportions as a results of the change in $q^{*}$ brought about by the change in wages that result from the change in $\lambda$. 
Note that throughout this analysis we are assuming that any change in wages brought about by the change in $\lambda$ does not alter how binding borrowing constraints are.

Let us consider the two lines in 3.1 separately. ${ }^{6} \quad$ Consider the first term in the square brackets: This term shows the effect on the number of children who become skilled of, ceteris paribus, replacing 2 su couples by one $s s$ and one $u u$ couple-which is what an increase in segregation does. If the relationship is concave in parental years of education (and as we shall show for the UK data it is), then an increase in sorting will tend to decrease the number of skilled children. Alternatively, this can be expressed as stating that if the production of skilled children has a negative cross-partial in each parent's years of education (i.e., if the marginal increase in the number of skilled children brought about by an increase in one parent's education is decreasing in the years of education of the other parent) then the number of skilled children will be maximized by mixing $s$ and $u$ individuals in couples rather than by creating homogenous couples.

The second term in the square brackets reminds us that what we are interested in is not the number of skilled children per se, but rather their proportion in the population. It gives the change in the aggregate economy's fertility rate as a result of an increase in segregation (i.e., the replacement of $2 s u$ couples by one $s s$ and one $u u$ couple). If this term is positive (we are subtracting it) it reinforces the negative first term as it shows that average fertility rate would increase thus ensuring that the smaller number of skilled children also translates into a smaller fraction of skilled children. Again, for our UK statistics this term is indeed positive.

The sign of the second line is given by the sign of $\frac{\partial \gamma^{*}}{\partial \theta}$ which indicates what happens to the differential between skilled and unskilled individuals' expected utility if, ceteris paribus, segregation is increased. At first blush, one might think that this term must be unambiguously positive. Skilled individuals will be made better off if they have a greater chance to meet with other skilled individuals (and thus enjoy higher household income with a greater probability). This intuition is correct. Where one's intuition may be misleading is in concluding that unskilled individuals will necessarily be made worse off. The effect on $V^{u}$ is actually ambiguous. Although unskilled individuals now have a lower chance of matching with skilled individuals and enjoying higher income through that match, if this probability was low in the first place because most matches were being rejected,

\footnotetext{
${ }^{6}$ The first line is the same as in Fernández and Rogerson (forthcoming) but the second has
} no counterpart there. 
then there is a positive counterpart to increased segregation. This counterpart is the fact that unskilled individuals need not waste their time (their matching opportunities) on a match that will happen only with a low probability and if rejected leaves them with a match quality of expected value $\mu$. Instead it allows a greater proportion of them to make better use of the two rounds by having their matches be only with other unskilled individuals and thus permitting them an expected match quality of $\int_{\mu}^{\bar{q}} q d Q+Q(\mu) \mu$.

More formally,

$$
\begin{aligned}
\frac{\partial \gamma^{*}}{\partial \theta} \equiv & \frac{\partial\left(V^{s}-V^{u}\right)}{\partial \theta}=\left(1-Q\left(q^{*}\right)\right)\left[\left(q^{*}-\mu\right)-\lambda\left(v_{s s}-2 v_{s u}-v_{u u}\right)\right]+ \\
& (2 \lambda-1)\left[\left(Q\left(q^{*}\right)-Q(\mu)\right) \mu-\int_{\mu}^{q^{*}} q d Q\right]
\end{aligned}
$$

Note that concavity of $v$ ensures that $v_{s s}-2 v_{s u}-v_{u u}$ is negative and thus that the expression in the first square brackets is positive. The ambiguity comes from the second term where the expression in the square brackets is negative, reflecting the gain in expected match quality-with probability $Q\left(q^{*}\right)$ the match would have been rejected by the skilled individual resulting in expected match quality $Q\left(q_{-}^{*}\right) \mu$ whereas with increased segregation the expected match quality is instead $\int_{\mu}^{\bar{q}} q d Q+Q(\mu) \mu$. Thus the sign of the second expression depends on whether $\lambda$ is greater or smaller than $1 / 2$. Note therefore that the expected utility differential will unambiguously increase if $\lambda$ is smaller than $1 / 2$. If $\lambda>.5$ and if $Q\left(q^{*}\right)$ is very close to one (i.e., skilled individuals reject almost all matches with unskilled individuals) then the differential can decrease. The reason that $\lambda>.5$ appears as a condition for the differential to fall is that both skilled and unskilled workers are made better of by the increase in expected match quality due to increased segregation. If, however, $1-\lambda$ was low, then skilled workers only had a low probability of meeting an unskilled workers whereas an unskilled worker has a high probability $(\lambda)$ of meeting a skilled worker. Thus, in order for the gain to unskilled workers to be greater than that to skilled workers requires $\lambda>1-\lambda$, i.e., $\lambda>.5$. Note that this requirement makes it relatively unlikely that $\frac{\partial \gamma^{*}}{\partial \theta}<0$ since $Q\left(q^{*}\right)$ is increasing in the wage differential and thus reaches its maximum at $\lambda=0$. Thus, in general, one would expect an increase in segregation to increase the relative attractiveness of becoming skilled.

To summarize, the effect of an increase in segregation is ambiguous. For the UK, in the absence of a supply response, $\lambda$ should fall. When there is a 
supply response, i.e., $\frac{\partial G}{\partial \gamma} \neq 0$, the effect is ambiguous. We now turn to the parameterization of our model.

\section{Parameterizing the Model}

In this section we parameterize our model by choosing parameter values so that the cross-sectional data generated by the steady-state of our model are consistent with those observed in actual UK data.

We proceed by constructing a sample of parents and children. Our primary data source is the British Cohort Study (BCS). This survey began with all children born between in one week in April 1970 in the UK. Parental education data was obtained from a retrospective questionnaire of parents conducted five years later in the BCS survey of 1975. The education data of children is obtained when these are 26 years old from the BCS 1996 survey. There they report their highest qualification level, which we map into years of education by considering how long it usually takes to obtain the stated level. In order to include a child in the sample we require both the data on parental and children educational attainment to be present. After eliminating the categories of "not known, not stated, or non-applicable", we were left with a sample of 6361 children with their respective parents. $^{7} \quad$ In general, if an individual indicated no qualifications, 10 years of educations were assigned. Individuals with any secondary qualifications were assigned 11 years; those with advanced vocational qualifications and some A level were assigned 13 years; those with a sub-degree level of further education (such as nursing and higher education diplomas) were assigned 15 years; whereas those with a degree and higher were assigned 16 years. ${ }^{8}$

From our BCS sample, we can calculate how correlated spouses are in their years of education (i.e., $\rho$ ). We find $\rho=.5$ which is lower than the 6 that we find for couples around the same age bracket in the US. Recall that the correlation of spouses in our model is given by $\rho=\theta+(1-\theta) Q\left(q^{*}\right)$. Thus, for the case in which all marital sorting is exogenous $\left(Q\left(q^{*}\right)=0\right)$ we set $\theta=.5$. For the case in which we allow both endogenous sorting and segregation, we set $\theta=.1$ implying that $Q\left(q^{*}\right)=\frac{4}{9}$.

Note that in the second case, the requirement that $\rho=.5$ and $q^{*}>\mu$ implies that for any positive choice of $\theta, Q$ must be a distribution such that the mean lies

\footnotetext{
${ }^{7}$ Each sibling in a pair of twins or higher multiple births was included as an independent observation.

${ }^{8}$ The details of the coding into years of education are available by request from the author.
} 
below the median. A simple distribution that possesses this property is the step distribution whose cdf is given by:

$$
\begin{aligned}
\frac{x}{2 a} & 0 \leq x<a \\
.5+\frac{x-a}{2(h-a)} & a \leq x \leq h
\end{aligned}
$$

for $a>\frac{h}{2}$. Of course, we would like to calibrate our function not just to a point but also to a slope. We have found no literature to guide us on this but find it useful to use the function above anyway. For all our experiments, this function will produce a constant frequency (since in the vecinity of the steady state the distribution is uniform), which seems like a reasonable assumption. That is, if skilled individuals increase their pickiness by $\Delta q$, they will decrease the fraction of unskilled individuals that they are willing to match with by an amount that is proportional to $\Delta q$.

Next we consider the choice of the $G_{i j}$ 's. Of course, we have no direct measure of these. Using our sample of parents and children, however, we can find the fraction of children from each family type that becomes skilled. In order to do this, we need to introduce a cutoff in achievement below which we consider an individual unskilled. We choose to call all individuals with at least two A levels (or their equivalent) skilled and all those below are considered unskilled. ${ }^{9}$ We find that this fraction is .77 for type $s s ; .52$ for type $s u$; and lastly .23 for type $u u$. Thus, we require the steady state of our model to satisfy $\Gamma_{s s}=.77, \Gamma_{s u}=.52$, and $\Gamma_{u u}=.23$. It is of interest to contrast these with the US where, defining as skilled anyone who has gone beyond a high-school degree, yields .81, .63 and .30 respectively.

In the absence of any knowledge of what the "correct" distribution of the $\gamma$ 's might be, we assume that they are uniformally distributed with different means. In addition to requiring these to match the $\Gamma_{i j}$ 's we also ask that in aggregate they produce a supply response that is in accordance with the literature in this area. We leave the description of the exact calibration to section 5.3.

Next we turn to the fertility profiles. As the BCS data does not have fertility of parents, we use the British Household Panel Survey (BHPS) of 1992 to examine this question. We construct a sample of women (with their partners) who were between the ages of 18 to 35 in 1970. The couple's fertility is then identified

\footnotetext{
${ }^{9}$ In our mapping from achievement to years of education, this is equivalent to considering skilled those individuals with more than 13 years of education.
} 
from the retrospective fertility data taken in 1992 and the education of the two partners in the couple is obtained. ${ }^{10}$ We find that the fertility of $s s$ couples is 2.07; that of su couples is 2.11; and that of $u u$ couples is 2.18. It is of interest to contrast this fertility profile with that of the US (respectively, 1.84, 1.90 and 2.26), not for the absolute numbers, but for the fact that it the UK's is far more similar across family types than that of the US.

We calibrate our fertility distributions by assuming that the fertility of a family type is a random draw from a binomial distribution over the two integers that bracket the average fertility rate for that type (i.e., either two or three for all types), such that the expected value of that distribution equals that family type's average fertility. Thus, $\eta_{2 s s}=.93, \eta_{2 s u}=.89$, and $\eta_{2 u u}=.82$.

Lastly, we choose to calibrate a constant elasticity of substitution production function:

$$
F\left(L_{s}, L_{u}\right)=A\left[b L_{s}^{\delta}+(1-b) L_{u}^{\delta}\right]^{\frac{1}{\delta}}
$$

which allows us to write the relative wages of skilled to unskilled workers (the skill premium) as:

$$
\frac{w_{s}}{w_{u}}=\frac{b}{1-b}\left(\frac{\lambda}{1-\lambda}\right)^{\delta-1}
$$

Based on data in Machin (1999), we match a skill premium of 1.8 as our benchmark. We also make use of the survey by Katz and Autor (1999) which suggests that a reasonable elasticity of substitution to match lies between 1 and 2.5. We choose to match an elasticity of substitution of 1.5 as our benchmark case, implying $\delta=1 / 3$. We also set the initial value of $w_{u}$ equal to 30,000 as a normalization.

We leave the discussion of the results of the parameterization of the model to the next section in which they are compared with the new steady state resulting from an increase in $\theta$.

\subsection{Welfare Analysis}

Both in order to evaluate welfare and to be able to examine the endogenous response in sorting resulting from an increase in the degree of segregation in the

\footnotetext{
${ }^{10} \mathrm{~A}$ bias of using this method is that we only obtain fertility data from couples that are still together in 1992.
} 
economy, we need to specify the household's utility function $v$. We choose to work with log utility, so:

$$
v(I)=\log I
$$

which implies that $q^{*}=\log \frac{2 \widetilde{w}_{s}}{\widetilde{w}_{s}+w_{u}}+\mu$. Note that an increase in $\widetilde{w}_{s}$ will decrease $q^{*}$ whereas an increase in $w_{u}$ will increase $q^{*}{ }^{11}$

There are several measures of welfare that are potentially of interest. The most important statistic to report is what happens to skilled and unskilled workers, i.e., $V^{s}$ and $V^{u}$. It is useful to convert the measure of the change in utility to the percentage change in all household incomes the individual would have to gain in the original steady state so as to be indifferent between it and the steady state that emerges as a result of a change in segregation. Thus, we can find $\Delta_{i} i \in\{s, u\}$ such that

$$
V^{i 0}\left(1+\Delta_{i}\right)=V^{i 1}
$$

where 0 indicates the original steady state and 1 indicates the new steady state. So, for example, we would solve for $\Delta_{s}$ by solving for its value that set $V^{s 0}(1+$ $\left.\Delta_{s}\right)=\left[\theta+(1-\theta) \lambda_{0}\right]\left[\log 2 \widetilde{w}_{s}\left(1+\Delta_{s}\right)+\int_{\mu}^{\bar{q}} q d Q+Q(\mu) \mu\right]+(1-\theta)\left(1-\lambda_{t+1}\right)[(1-$ $\left.\left.Q\left(q^{*}\right)\right) \log \left(\widetilde{w}_{s}+w_{u}\right)\left(1+\Delta_{s}\right)+\int_{0}^{\bar{q}} q d Q+Q\left(q^{*}\right)\left(\log 2 \widetilde{w}_{s}\left(1+\Delta_{s}\right)+\mu\right)\right]$ equal to $V^{s 1}$. It is easy to show that

$$
\log \left(1+\Delta_{i}\right)=V^{i 1}-V^{i 0}
$$

Another interesting measure of welfare is an individual's ex-ante welfare. That is, we can think of the individual as having a probability of being born to a family type $i j$ as given by $\frac{\varphi_{i i} f_{i j}}{\sum_{i j} \varphi_{i j} f_{i j}}$ and then becoming skilled with probability $\Gamma_{i j}\left(\gamma^{*}, \lambda\right)$ and obtaining expected utility $V^{s}-\frac{\int_{0}^{\gamma^{*}} \gamma d G_{i j}}{G_{i j}\left(\gamma^{*}\right)}$ in that case, and becoming unskilled with probability $1-\Gamma_{i j}\left(\gamma^{*}, \lambda\right)$ and obtaining expected utility $V^{u}$. Summing over all the family types, we obtain that an (unborn) individual's ex-ante utility, $U$, is given by:

\footnotetext{
${ }^{11}$ Given our choice of utility function, we finish our calibration of the distribution of quality by choosing an arbitrary initial value for $a$, say $\underline{a}=\frac{72}{5} \log \frac{2 \widetilde{w}_{c}}{\widetilde{w}_{s}+w_{u}}$ (using steady-state wages to evaluate the expression), yielding $h=8 \_Q\left(q^{*}\right)-2 \_-4 \log \frac{2 \widetilde{w}_{s}}{\widetilde{w}_{s}+w_{u}}$.
} 


$$
\lambda V^{s}+(1-\lambda) V^{u}-\frac{\sum_{i j} \varphi_{i j} f_{i j} \frac{\Gamma_{i j}\left(\gamma^{*}, \lambda\right)}{G_{i j}\left(\gamma^{*}\right)} \int_{0}^{\gamma^{*}} \gamma d G_{i j}(\gamma)}{\sum_{i j} \varphi_{i j} f_{i j}}
$$

Again we can convert the change in ex-ante expected utility in the pre and post increased segregation steady states by solving for the fraction $\Delta$ that an individual have to obtain from all household incomes in the original steady state so as to be indifferent between the two steady states $\left(U^{0}\right.$ and $\left.U^{1}\right)$. As before, it is easy to show that $\Delta$ solves $\log (1+\Delta)=U^{1}-U^{0}$. Note that the last term in expression (4.1) is the expected disutility from the effort cost to become skilled. As we will need to refer to it in our welfare calculations, we shall henceforth denote it by $W\left(\gamma^{*}, \lambda\right)$.

\section{Response to an Increase in Segregation}

We will be examining three different possible scenarios. The first is one in which almost all behavior is exogenous in that both the supply response is fixed and the degree of sorting is not affected by any changes in the environment. In the second scenario, we allow for sorting to respond to incentives, but keep the supply response of factors fixed. In the last scenario, both relative supplies of factors and the degree of sorting respond to their environment.

In all cases the calibration procedure is similar. The parameters $A, b, \delta, \theta$ and the steady state value of $\lambda$ are determined by the wage premium, the normalization of the initial value of the unskilled wage, the elasticity of substitution, the correlation of spouses in their years of education, and the $\Gamma_{i j}$ values. This will uniquely determine steady-state $\lambda$ and is the extent of the calibration needed for the first scenario. The second scenario endogenizes the degree of sorting. This is done by introducing a quality distribution $Q(q)$. As discussed previously, we calibrate it by requiring that when combined with an initial choice on the degree of segregation $\theta=.1$ and evaluated at $q^{*}$ (i.e., the value of match quality such that a skilled individual is indifferent between matching with an unskilled individual and obtaining a match with another skilled individual with match quality $\mu$ as specified in equation (2.2)), it matches the correlation of spouses found in the data. Note that this procedure yields an equilibrium difference in $V^{s}$ and $V^{u}$

(i.e., $\gamma^{*}$ ). Thus, our last exercise is to introduce a supply response in terms of a distribution of $\gamma^{\prime}$ 's given by $G_{i j}$ 's such that when evaluated at $\gamma^{*}$ they yield the $\Gamma_{i j}$ 's and the supply response observed in the data. 


\subsection{Exogenous sorting and supply response}

We first examine the consequences in changes in the degree of segregation in an economy in which almost all behavior is exogenously specified. That is, we will explore the effect of an increase in environmental segregation (i.e., $\theta$ ) assuming that there is no endogenous component to sorting, i.e., $Q\left(q^{*}\right)=0$ and hence $\rho=\theta$, i.e., the degree of segregation is the same as the degree of correlation of spouses. In addition we assume that there is no endogenous response of the $\Gamma_{i j}$ 's to the change in sorting. This assumption can be made consistent with microeconomic foundations, but for the moment we can simply interpret this constancy as the outcome of some socioeconomic/genetic process such that the $\Gamma_{i j}$ 's are constant. ${ }^{12}$ Thus, changes in the relative supplies of skilled and unskilled labor are governed by changes in the relative frequency of different family types. This is a very useful benchmark as it is the most "mechanical" approach that still respects the fact that there are fertility differentials as well as propensities for children to become skilled that differ across family types. Furthermore, this will allow for an easy comparison with the results obtained for the US by Fernández and Rogerson (forthcoming).

Table 1 below reports the results of the calibration in the first row and the response to an increase in segregation (equivalent here to the correlation of spouses in their years of education) from .5 to .6 in the second row.

Table 1

Increase in Segregation: Exogenous Responses

\begin{tabular}{|l|l|l|l|l|l|l|l|}
\hline & $\lambda$ & $w_{s}$ & $w_{u}$ & $s t d \log y$ & $s t d \log y$ & $V_{s}$ & $V_{u}$ \\
\hline$\theta=.5$ & 0.49161 & 54000 & 30000 & 0.29385 & 0.25536 & 11.509 & 11.082 \\
\hline$\theta=.6$ & 0.48823 & 54179 & 29828 & 0.29834 & 0.26766 & 11.523 & 11.061 \\
\hline$\Delta_{s}=0.0149$ & \multicolumn{8}{c|}{$\Delta=-0.0049$} \\
\hline
\end{tabular}

The results of the baseline calibration yields around $49 \%$ of individuals who are skilled. This is a bit higher than the $41 \%$ reported by Green and Steedman (1997) as the fraction of 18 year olds that have attained 2 A levels or level 3 Vqs in England in 1995, but the trend toward higher qualifications is increasing so the figure may be higher when a new "steady state" is attained. The standard deviation of $\log$ income is small relative to its actual value of .5 in the national

\footnotetext{
${ }^{12}$ In Fernandez and Rogerson (forthcoming) individuals either have or do not have ability to become skilled (e.g., $\gamma \in\{0,1\}$ ). Thus a child's $\gamma$ can be considered a draw from a binomial distribution $G_{i j}$.
} 
labor force survey, but that is to be expected since all the variation in personal income in the model is produced by two wages only.

Next we turn to the consequences of an increase in the degree of segregation. We know from the theory discussed previously, that an increase in segregation will necessarily decrease $\lambda$ if $f_{s s} \Gamma_{s s}-2 f_{s u} \Gamma_{s u}+f_{u u} \Gamma_{u u}$ is negative and $\left(f_{s s}-2 f_{s u}+f_{u u}\right)$ is positive. Using the UK numbers for these parameters we obtain -. 1198 and 0.3 respectively. Thus, an increase in $\theta$ will unambiguously decrease the proportion of skilled people in the new steady state.

As shown in row 2 of Table 1, the effect of an increase in the correlation of spouses is to decrease $\lambda$ from .492 to .488 (around $0.69 \%$ ). This increases the skilled wage by $.33 \%$, decreases the unskilled wage by $.57 \%$, and serves to increase the inequality in the personal income distribution as measured by the standard deviation of $\log y$ (as shown in column 4) and in the distribution of family income (as shown in column 5 by $\log f y$ ). The standard deviation of personal log income increases by $1.52 \%$ and that of family income increases by $4.81 \%$. Skilled workers are made better off (they would require a $1.5 \%$ increase in household incomes to be as well off in the original steady state); unskilled workers are made worse off (they would require a $2 \%$ decrease in the original steady-state household incomes to be indifferent). Ex-ante welfare falls and a .5\% decrease in the original steady-state household incomes would be required to create indifference.

Although the change in the income distribution is not negligible, the response of the individual income distribution is small relative to what we found for the US (close to a $5 \%$ increase for an increase in $\theta$ from .6 to .7). Of course, that calibration was to different parameters for the wage premium and $\theta$, but the main difference stems from the fertility and $\Gamma_{i j}$ profiles as noted earlier.

The easiest way to understand the contributions of the fertility and $\Gamma_{i j}$ profiles is by calibrating the steady state of the model using some of the US statistics. In Table 2 below, we show the result of replacing the UK fertility profile by the US one, recalibrating the model and increasing $\theta$ to .6. Now the increase in segregation produces an increase in the standard deviation of the log of personal income of around $2.22 \%$. Skilled workers' welfare improves by more than before; unskilled workers' welfare fall by more. The decrease in ex ante welfare is likewise greater. 
Table 2

Increase in Segregation: Exogenous Responses US fertility, UK $\Gamma_{i j}$

\begin{tabular}{|l|l|l|l|l|l|l|l|}
\hline & $\lambda$ & $w_{s}$ & $w_{u}$ & $s t d \log y$ & $s t d \log y$ & $V_{s}$ & $V_{u}$ \\
\hline$\theta=.5$ & 0.4574 & 54000 & 30000 & 0.29282 & 0.25529 & 11.504 & 11.076 \\
\hline$\theta=.6$ & 0.4523 & 54293 & 29756 & 0.29932 & 0.26925 & 11.522 & 11.054 \\
\hline \multicolumn{10}{|c|}{$\Delta_{u}=-0.0218$} & \multicolumn{5}{c|}{$\Delta=-0.0064$} \\
\hline
\end{tabular}

Even more dramatically, as shown in Table 3, if we replace instead the UK's $\Gamma_{i j}$ profile with that of the US (keeping the UK fertility profile) and recalibrate the model, an increase in $\theta$ to 0.6 now produces an increase in personal inequality of $4.20 \%$.

It is interesting to think about what the difference in the US and UK $\Gamma_{i j}$ profiles imply. The important thing to note is not the fact that these numbers are larger for each family type in the US than in the UK nor the slope of the relationship, but rather that in the US a child's chances of becoming skilled are relatively more improved by switching from $u u$ parents to $s u$ parents than by switching from su parents to $s s$. In the UK, on the other hand, it is almost as significant to switch from $u u$ parents to $s u$ ones as it is to switch from $s u$ parents to ss parents. That it, the US relationship is more concave than the UK one, and hence an increase in segregation will have more important effects there than for the UK. The easiest way to see this is by examining the ratio between $\Gamma_{s u}$ and $\frac{\Gamma_{s s}+\Gamma_{u u}}{2}$ which is 1.135 for the US whereas it is 1.0505 for the UK (a linear relationship would yield a ratio of 1 ).

Table 3

Increase in Segregation: Exogenous Responses

UK fertility, US $\Gamma_{i j}$

\begin{tabular}{|l|l|l|l|l|l|l|l|}
\hline & $\lambda$ & $w_{s}$ & $w_{u}$ & $s t d \log y$ & stdlogf $y$ & $V_{s}$ & $V_{u}$ \\
\hline$\theta=.5$ & 0.6384 & 54000 & 30000 & 0.28239 & 0.24194 & 11.527 & 11.106 \\
\hline$\theta=.6$ & 0.6308 & 54286 & 29503 & 0.29427 & 0.26121 & 11.539 & 11.071 \\
\hline \multicolumn{10}{|c|}{$\Delta_{u}=-0.0342$} & $\Delta=-0.0082$ \\
\hline
\end{tabular}

Lastly, Table 4 shows the result of using both the US fertility and $\Gamma_{i j}$ profiles. In this case the effect of the increase in the degree of segregation is to increase personal inequality by $5.38 \%$, even more than what Fernández and Rogerson obtained for the US. 
Table 4

Increase in Segregation: Exogenous Responses

US fertility, US $\Gamma_{i j}$

\begin{tabular}{|l|l|l|l|l|l|l|l|}
\hline & $\lambda$ & $w_{s}$ & $w_{u}$ & $s t d \log y$ & $s t d \log y$ & $V_{s}$ & $V_{u}$ \\
\hline$\theta=.5$ & 0.6098 & 54000 & 30000 & 0.28671 & 0.24632 & 11.523 & 11.101 \\
\hline$\theta=.6$ & 0.5995 & 54112 & 29370 & 0.23021 & 0.26882 & 11.538 & 11.063 \\
\hline$\Delta_{s}=0.0147$ & $\Delta_{u}=-0.0372$ & \multicolumn{5}{c|}{$\Delta=-0.01070$} \\
\hline
\end{tabular}

Note that in all cases the increase in the inequality of the distribution of family income is much greater than that in personal income. This is due to the fact that not only does the income of unskilled individuals fall, but also the probability of a mixed household (skilled with unskilled) decreases thereby exacerbating the inequality in family income.

\subsection{Endogenous Sorting}

The second analysis allows sorting to be endogenous. In order to examine the effect of an increase in segregation when sorting is endogenous, we arbitrarily set $\theta=.1$ and thus obtain $Q\left(q^{*}\right)=\frac{4}{9}$ resulting in a correlation of spouses equal to .5 . Now we increase of $\theta$ from .1 to a value such that, if there were no endogenous response in sorting, would produce a correlation of spouses of .6. This occurs at $\theta=.28$. Table 5 below shows the result of the increase in segregation in the new steady state.. 
Table 5

Increase in Segregation: Endogenous Sorting

\begin{tabular}{|c|c|c|}
\hline & $\theta=.1$ & $\theta=.28$ \\
\hline$\lambda$ & 0.49161 & 0.48822 \\
\hline$w_{s}$ & 54000 & 54179 \\
\hline$w_{u}$ & 30000 & 29828 \\
\hline stdlog $y$ & 0.29385 & 0.29835 \\
\hline std $\log f y$ & 0.25536 & 0.26769 \\
\hline$q^{*}$ & 3.1309 & 3.1342 \\
\hline$Q\left(q^{*}\right)$ & 0.4444 & 0.4449 \\
\hline$\rho$ & 0.5000 & 0.6002 \\
\hline$V_{s}$ & 14.984 & 14.999 \\
\hline$V_{u}$ & 14.557 & 14.537 \\
\hline \multicolumn{3}{|c|}{$\Delta_{s}=0.0153 \quad \Delta_{u}=-0.0205$} \\
\hline
\end{tabular}

Note that the increased segregation now produces a correlation of spouses that slightly exceeds .6 as skilled individuals react to the increased wage inequality by becoming pickier (i.e., requiring a higher $q^{*}$ ) in order to accept a match with an unskilled individual. This causes $\lambda$ to fall by very slightly more than in the first case as even fewer matches between skilled and unskilled individuals are formed. Unskilled individuals would be willing to give up around $2.18 \%$ of household income to return to the original steady state, whereas skilled individuals would be willing to give up around $1.7 \%$ of income to maintain the new steady state. These last numbers differ more than others did compared with their counterparts in Table 1 since they reflect the fact that individuals obtain utility from the quality of their matches as well as from income and thus a change in segregation affects utility through this channel as well.

\subsection{Endogenous Sorting and Supply}

The last analysis we perform is to allow both sorting and the $\Gamma_{i j}$ 's to respond to the change in segregation. Note that incorporating an endogenous supply response does not require us to recalibrate the entire model; it simply requires us to calibrate the $G_{i j}$ 's so that when evaluated at $\gamma^{*}$ it matches the parameter values given by the data described below. ${ }^{13}$ Throughout we will assume that the

\footnotetext{
${ }^{13} \gamma^{*}$ is the difference between $V^{s}$ and $V^{u}$ produced in the steady-state of the calibrated model.
} 
changes observed in wages do not change the bindingness of borrowing constraints.

We assume that the $\gamma$ 's are uniformly distributed with a cumulative distribution given by $G_{i j}(\gamma)=\frac{\gamma-a_{i j}}{k-a_{i j}}$. We calibrate the three $a_{i j}$ 's and the $k$ by using four statistics. The first three statistics are the fractions of children of each family type that become skilled, i.e., the $\Gamma_{i j}$ 's given by the data. We require that the $G_{i j}$ 's evaluated at the steady-state level of $\gamma^{*}$ (and given an assumption about how binding borrowing constraints are across different family and fertility types) match the $\Gamma_{i j}$ 's given by the data. ${ }^{14}$ The last statistic is much more problematic. We would like to know what the supply response of skilled labor is to something like a change in the skill premium or a change in $p$. These numbers very much depend on the model one is estimating.

In the absence of any parameter estimates for the UK, we rely primarily on Kane (1994) who examines the college enrollment of 18-19 year olds from 1973 to 1988 in the US. Using a pooled time series cross-section of states (which provides variation in tuition costs and enrollment), Kane estimates a probit model of finishing high school and attending college. He is then able to examine the simulated effects of an increase in tuition. He finds that an increase in tuition of $\$ 1000$ decreases the enrollment of whites by about 3\%. We translate this tuition decrease into a percentage increase in the income differential of skilled and unskilled individuals by converting this number into a change in this differential. Given an average income differential of around $\$ 10,000$ over this period, we have a $10 \%$ change in the income differential. Thus, we calibrate our $G_{i j}$ 's by requiring that a change in skilled individuals' income from $\$ 54000$ to $\$ 56400$ (keeping the unskilled wage fixed at 30000), yield a $3 \%$ increase in the fraction of skilled individuals. The utility differential is generated not only by the change in skilled wages, but also by the fact that any labor supply change will also change the matching probabilities. We maintain the frequencies of the different family types fixed at their original level. This procedure yields us the $a_{i j}$ 's and the $k$.

Kane also finds though that the effect of a dollar in earnings differentials was worth roughly $1 / 5 t h$ of a dollar change in net direct costs in terms of how responsive individuals were to attending college. In terms of net present value, however, his calculations indicate that a dollar increase in the initial earnings differential should be worth roughly $\$ 5.20$ in direct costs. Thus, individual are responding by $1 / 26$ less to a change in tuition then to a change in direct costs when translated to net present value. This suggests that our change of wages from $\$ 54000$ to $\$ 56400$ should produce a $0.115 \%$ increase in the fraction of skilled

\footnotetext{
${ }^{14} \gamma^{*}$ is the difference between $V^{s}$ and $V^{u}$ produced in the steady-state of the calibrated model.
} 
individuals. We thus repeat our calibration using $0.15 \%$ (slightly larger than above) as our parameter estimate.

It is difficult to place a great deal of trust in any of these parameters. Heckman, Lochner and Taber (1998), for example, develop a general equilibrium model of skill formation with heterogeous ability and on-the-job investment. Calibrating their model and simulating they conclude that a tuition increase of $\$ 1000$ would decrease the probability of attending college by about 0.07 on average. But their calibration also implies that agents with ability in the second quartile from the bottom would, on the basis of net present value of earnings, find it advantageous to be unskilled workers and not attend college whereas those with lower ability (in the bottom quartile) would be better off going to college. Lastly Lee (2001) in a similar model but without on-the-job-investment and with the option for agents to stay home, finds that an increase in the skill premium of $24.5 \%$ increased the proportion of those who had attained at least one year of college from $39.6 \%$ to $42.6 \%$, i.e., a proportionately $7.6 \%$ increase. Again, in terms of our model this would imply that an increase in the skilled wage to $\$ 56400$, keeping the unskilled wage fixed (i.e., a $4.4 \%$ increase in the skill premium) should increase the fraction of skilled workers by $1.36 \%$ which evaluated at our initial steady state implies an increase in the workforce of $.67 \% .^{15}$

Below we report our results parameterized to two different cases. The first which we call "large response" is to produce an increase of 3\%; the second, denoted by "small response" is to produce an increase of $.15 \%$.

We specify borrowing constraints as $I-c n \geq m p$ where $c$ is some minimum consumption level required by each child in the family. As this is an inequality (and we are not using data to match either $c$ or $p$, nor are we examining the effect of changes in constraints), then in general, any particular $\Gamma_{i j}$ number does not have a unique decomposition into a parameter of a given distribution and a assumption about how binding is the borrowing constraint. For any distribution $G_{i j}$, the requirement that $\Gamma_{i j}=\frac{G_{i j}\left(\gamma^{*}\right)}{f_{i j}} \sum_{n=0}^{n=\bar{n}} \min [m, n] \eta_{n i j}$ can be decomposed several ways into a family background and a borrowing constraint component. ${ }^{16}$

Table 6 below shows three such decompositions for our calibrated uniform distributions for both the large and small response case. The first column assumes

\footnotetext{
${ }^{15}$ The calculations for the increase in the proportion of skilled workers in resonse to the change in the skill premium were done by Donghong Lee (personal correspondance) based on the model and results from his thesis (2001).

${ }^{16}$ For all our calculations we arbitrarily set $p=1000$.
} 
that the observed $\Gamma_{i j}$ 's are the result only of family background; there are no borrowing constraints (this is indicated by setting the maximum number of skilled children that parents can produce equal to the total number of children, i.e., $\left.m_{n i j}=n\right)$. The second column is generated by assuming that there are mild borrowing constraints in that $u u$ families with three children can at most afford to finance the acquisition of skills for two of them. Note that the assumption of mild credit constraints for $u$ families shifts their mean downwards as implied by the assumption that their lower rate of production of skilled children reflects not only parental background as reflected in the distribution of the $\gamma$ 's but also the existence of borrowing constraints. The last column assumes that both su and $u$ families with three children can afford to produce a maximum of two skilled children. ${ }^{17}$

Table 6

Decomposition of $\Gamma_{i j}$ 's into Means and Borrowing Constraints

\begin{tabular}{|c|c|c|c|}
\hline large response & $m_{n i j}=n$ & $m_{3 u u}=2$ & $m_{3 u u}=2, m_{3 s u}=2$ \\
\hline$\mu_{s s}$ & 0.3658 & 0.3658 & 0.3658 \\
\hline$\mu_{s u}$ & 0.4247 & 0.4247 & 0.4210 \\
\hline$\mu_{u u}$ & 0.4469 & 0.4459 & 0.4459 \\
\hline small response & $m_{n i j}=n$ & $m_{3 u u}=2$ & $m_{3 u u}=2, m_{3 s u}=2$ \\
\hline$\mu_{s s}$ & -1.1652 & -1.1652 & -1.1652 \\
\hline$\mu_{s u}$ & 0.36580 & 0.3658 & 0.2688 \\
\hline$\mu_{u u}$ & 0.9425 & 0.9161 & 0.9161 \\
\hline
\end{tabular}

We will use the second column of Table 6 as our benchmark. Note that the borrowing constraints in this scenario are very mild in that only those $u u$ families with 3 children are affected, and only if their children have $\gamma<\gamma^{*}$. This is less than $2 \%$ of the population.

The introduction of an endogenous supply response to the change in incentives radically alters the results of our first two analyses. Table 7 below shows the effect

\footnotetext{
${ }^{17}$ The fact that the means are negative comes from the calibration procedure. To accomodate a small labor supply response some of the $a_{i j}$ 's are negative. This is not problematic from the point of view of the model; it simply implies that some individuals enjoy becoming skilled and thus will do so even if the differential is zero or negative. In any case, it is easy to get rid of this feature by transforming the uniform distribution to a step function with all those individuals now below zero now distributed uniformly between zero and some positive number smaller than $\gamma^{*}$. This transformation would leave the calibration unchanged and thus all the results unchanged except our calculation of $W$ and hence $U$.
} 
of an increase in segregation from its initial steady state value of .1 to .28 which, as before, is the value of $\theta$ that would be required to produce a correlation of spouses of .6 if there were no reaction of individuals to the change in segregation.

We discuss both cases of Table 7 in turn. Turning first to Table 7a, the first result to note is that $\lambda$ now increases by $2.5 \%$ rather than dropping by $.7 \%$ as it did in the exercise of the previous section. There are two effects here: the first is the one we have analyzed previously, that is, ceteris paribus, an increase of correlation of types causes a destruction of mixed marriages which leads to a lower average production of skilled children as a fraction of the population. The second effect is a new one: ceteris paribus, the increase in segregation makes it relatively more attractive to become skilled (i.e., $\gamma^{*}(\lambda)$ increases for a given $\lambda$ ) as now a skilled person will be more sure of being matched with another skilled individual (whereas this probability decreases for an unskilled individual). Thus, the first effect is to decrease $\lambda$ whereas the second effect is to increase it.

The two effects are shown in Figure 2. The first effect is seen in that the $\Psi$ curve shifts up since a greater value of $\gamma$ is required to produce a given $\lambda$ given that $f_{s s} \Gamma_{s s}-2 f_{s u} \Gamma_{s u}+f_{u u} \Gamma_{u u}$ is negative and $\left(f_{s s}-2 f_{s u}+f_{u u}\right)$ is positive. The shift of this curve shows the negative effect of replacing 2 us couples with one uu and one $s s$ couple from the point of view of producing a greater skilled fraction of the population. The second effect is shown in the the shift upwards of the $V^{s}-V^{u}$ curve indicating the increase in the relative attractiveness of becoming skilled for a given $\lambda$. As can be seen in the figure, the shifts of these two curves necessarily increases $\gamma^{*}$ (i.e., the differential in utilities between a skilled and an unskilled person), but the net effect on $\lambda$ depends on which curve shifts more. As is clear from the result of our analysis above, for our choice of functional forms and the UK numbers, the second effect dominates for both cases of Table 7 .

As a result of the $\lambda$ increase, the skilled wage drops by $.12 \%$ whereas the unskilled wage increases by $2.1 \%$. This has a strong effect on the personal income distribution as can be seen by the fact that the standard deviation of log income falls by over $5.6 \%$. The narrowing of the skill premium makes skilled individuals less picky (i.e., $q^{*}$ falls) so that the correlation of spouses rises to .5987 rather than to .6. Although the welfare lost due to effort (i.e., $W$ ) is higher in the new steady state, this is due to the fact that more people find it attractive to become skilled. In this scenario everyone is made better off as can be by the fact that all the $\Delta$ 's are positive. This is despite the fall in the skilled wage as the increase in segregation more than compensates for this. ${ }^{18}$

\footnotetext{
${ }^{18}$ Note though that to examine the effect on the representative skilled person from family type
} 
The story told in Table $7 \mathrm{~b}$, however, is rather different. The smaller increase in $\lambda(1.3 \%)$ resulting from the increase in segregation translates into a smaller decrease in the skilled wage $(.6 \%)$ and a smaller increase in the unskilled wage $(1.1 \%)$. As before, the expected utility of a skilled person increases. What is interesting to note, however, is that despite the wage increase unskilled individuals are on the whole left worse off . Although they earn more, they are also less likely to marry a skilled person, and this second effect outweighs the first. ${ }^{19}$ Unskilled individuals would be willing to give up $.58 \%$ of their original steady-state household income in order to remain in that steady state. Skilled individuals, on the other hand, are made better off despite the fall in skilled wages as they are now more sure of matching with another skilled individual. They would be willing to sacrifice $.84 \%$ of the original steady state household income to change to the new steady state. A surprising feature of Table $7 \mathrm{~b}$ is that the welfare lost due to effort $W$ actually falls despite the fact that more people are becoming skilled. This is due to the change in the frequency of family types. As a result of the increase in $\lambda$ and $\theta$, there is a larger proportion of $s s$ types which implies a tilt towards a lower cost of becoming skilled.

In both supply cases, the inequality in utility increases despite the decrease in income inequality as can be seen by the fact that $\gamma^{*} \equiv V^{s}-V^{u}$ increases. For the first time, however, the ex-ante expected utility of an unborn individual is higher in the new steady state (in both cases); all household incomes would have to be increased by $.55 \%$ and $.36 \%$ in the original steady state in order to achieve indifference with the new steady state for the large and small response cases respectively.

$i j$ requires not only examining what happens to $V^{s}$ but rather to $V^{s}-\frac{\int_{0}^{\gamma^{*}} \gamma d G}{G_{i j}\left(\gamma^{*}\right)}$ since this will take into account the expected effort cost contingent on becoming skilled.

${ }^{19}$ Since their chances of marrying a skilled person were not insignificant, the increased segregation does not have the effect of making them better off by preserving 2 effective rounds in which to obtain a better than average quality match. 
Table $7 a$

Increase in Segregation: Endogenous Responses-Large response

\begin{tabular}{|r|r|r|}
\hline & $\theta=.1$ & $\theta=.28$ \\
\hline$\lambda$ & 0.4916 & 0.5040 \\
\hline$w_{s}$ & 54000 & 53350 \\
\hline$w_{u}$ & 30000 & 30644 \\
\hline$s t d \log y$ & 0.29385 & 0.27721 \\
\hline$s t d \log f y$ & 0.25536 & 0.24824 \\
\hline$q^{*}$ & 3.131 & 3.119 \\
\hline$Q\left(q^{*}\right)$ & 0.4444 & 0.4427 \\
\hline$\rho$ & 0.5000 & 0.5987 \\
\hline$\gamma^{*}$ & 0.427 & 0.428 \\
\hline$V_{s}$ & 14.985 & 14.989 \\
\hline$V_{u}$ & 14.558 & 14.561 \\
\hline$W$ & 0.1809 & 0.1844 \\
\hline$U$ & 14.587 & \\
\hline$\Delta_{s}=0.0042 \Delta_{u}=0.0033$ & $\Delta=0.0055$ \\
\hline \multicolumn{2}{|r}{} \\
\hline
\end{tabular}

Table $7 b$

Increase in Segregation: Endogenous Responses-Small response

\begin{tabular}{|r|r|r|}
\hline & $\theta=.1$ & $\theta=.28$ \\
\hline$\lambda$ & 0.4916 & 0.4980 \\
\hline$w_{s}$ & 54000 & 53664 \\
\hline$w_{u}$ & 30000 & 30329 \\
\hline$s t d \log y$ & 0.29385 & 0.28531 \\
\hline$s t d \log y$ & 0.25536 & 0.25568 \\
\hline$q^{*}$ & 3.131 & 3.124 \\
\hline$Q\left(q^{*}\right)$ & 0.4444 & 0.4436 \\
\hline$\rho$ & 0.5000 & 0.5994 \\
\hline$\gamma^{*}$ & 0.427 & 0.441 \\
\hline$V_{s}$ & 14.985 & 14.993 \\
\hline$V_{u}$ & 14.558 & 14.552 \\
\hline$W$ & -0.5477 & -0.5794 \\
\hline$U$ & 15.315 & 15.351 \\
\hline \multicolumn{2}{|r|}{} \\
\hline$\Delta_{s}=0.0084 \Delta_{u}=-0.0058$ & $\Delta=0.0363$ \\
\hline
\end{tabular}




\subsection{Robustness}

We have checked the robustness of our results to various assumptions. For example, instead of assuming that individuals from $u$ families are mildly constrained, we have assumed that there are no borrowing constraints for any family types. The results are very similar. As shown in our first exercise, the numbers obtained are sensitive to the fertility distribution and to the degree of concavity of the $\Gamma_{i j}$ 's. Changes in the elasticity of substitution of labor types in the production function affect the impact of a change in $\lambda$ on the skill premium and hence on the income distribution.

\section{Conclusion}

This paper presents a model of the intergenerational transmission of education and marital sorting where parents matter both because of their household income and because parental human capital determines the expected value of a child's disutility from making an effort to become skilled. We show that an increase in segregation has potentially ambiguous effects on the fraction of individuals that become skilled in the steady state, and hence on marital sorting, the personal and household income distribution, and welfare.

We calibrate the steady-state of our model to UK statistics and compare a version of the model to the results obtained previously for the US. We find that segregation is likely to have a smaller negative impact in the UK than in the US as a result of the fertility and education transmission process. In the model in which both sorting and education is endogenous, we find that an increase in segregation will lead to a higher fraction of skilled individuals, a more compressed income distribution, and higher welfare for skilled individuals. The effect on the welfare of unskilled individuals depends on the size of the supply response. For a large response, their utility increases; for a small response, unskilled individuals are made worse off despite the increase in their wage. 


\section{References}

[1] Aiyagari, S. Rao, J. Greenwood, and N. Guner. "On the State of the Union." Journal of Political Economy, 108 (2000), 213-244.

[2] Alesina, Alberto, and Eliana La Ferrara, "Participation in Heterogeneous Communities," Quarterly Journal of Economics, CXV (2000), 847-904.

[3] Bénabou, Roland, "Heterogeneity, Stratification and Growth," American Economic Review, LXXXVI (1996), 584-609.

[4] Bisin, Alberto and Thierry Verdier, "Beyond the Melting Pot: Cultural Transmission, Marriage, and the Evolution of Ethnic and Religious Traits," Quarterly Journal of Economics CXV (2000), 955-87.

[5] Burdett. Ken, and Melvyn Coles, "Marriage and Class," Quarterly Journal of Economics, CXII (1997), 141-68.

[6] - - - - - - -, "Transplants and Implants: The Economics of SelfImprovement," mimeo, (1999).

[7] Cole, Harold, George Mailath, and Andrew Postlewaite, "Social Norms, Savings Behavior and Growth," Journal of Political Economy, C (1992), $1092-$ 1125 .

[8] Cooper, Suzanne, "A Positive Theory of Income Redistribution," Journal of Economic Growth, III (1998), 171-195.

[9] Durlauf, Steven, "A Theory of Persistent Income Inequality," Journal of Economic Growth, I (1995), 75-93.

[10] Fernández, Raquel, "Sorting, Education and Inequality," in Advances in Economic Theory, Dewatripont, Hansen, and Turnovsky (Eds.), Cambridge University Press, forthcoming, 2001.

[11] ------, Nezih Guner, and John Knowles, "Love and Money: A Theoretical and Empirical Analysis of Household Sorting and Inequality," mimeo, 2001.

[12] ------and Richard Rogerson, "Income Distribution, Communities and the Quality of Public Education," Quarterly Journal of Economics, CXI (1996), $135-164$. 
[13] _-_____-_- "Education Finance Reform: A Dynamic Perspective," Journal of Policy Analysis and Management, XVI (1997), 67-84.

[14] -_-_-_-_- "Public Education and Income Distribution: A Dynamic Quantitative Evaluation of Education Finance Reform," American Economic Review, LXXXVIII (1998), 813-833.

[15] -_-_-_---, "Sorting and Long-Run Inequality," Quarterly Journal of Economics, forthcoming.

[16] Green, Andy and Hilary Steedman, "Into the Twenty First Century: An Assessment of British Skill Profiles and Prospects," Center for Economic Performance, March 1997.

[17] Greenwood, Jeremy, Nezih Guner and John Knowles, "More on Marriage, Fertility, and the Distribution of Income," University of Rochester, mimeo, (1999).

[18] Heckman, J., L. Lochner, and C. Taber, "Explaining Rising Wage Inequality: Explorations with a Dynamic General Equilibrium Model of Labor Earnings with Heterogeneous Agents," Review of Economic Dynamics, 1(1) (1998), $1-58$.

[19] Jargowsky, Paul, "Take the Money and Run: Economic Segregation in US Metropolitan Areas," American Sociological Review, LXI (1996), 984-998.

[20] Kane, T., "College Entry by Blacks since 1970: The Role of College Costs, Family Background, and the Returns to Education," Journal of Political Economy, 102(5) (1994), 878-911..

[21] Katz, Larry and David Autor, "Changes in the Wage Structure and Earnings Inequality," in Handbook in Labor Economics, volume 3A, edited by Orley Ashenfelter and David Card, (Amsterdam: North-Holland, 1999).

[22] Kremer, Michael, "How Much Does Sorting Increase Inequality," Quarterly Journal of Economics, CXII (1997), 115-139.

[23] ----- and Eric Maskin, "Wage Inequality and Segregation by Skill," Harvard University mimeo, 1996. 
[24] Lee, Donghoon, "An Estimable Dynamic General Equilibrium Model of Work, Schooling and Occupational Choice" mimeo, University of Pennsylvania, 2001.

[25] Machin, Steve 'Wage Inequality in the 1970s, 1980s and 1990s', in P. Gregg and J. Wadsworth (eds.) The State of Working Britain, Manchester University Press, 1999.

[26] Mare, Robert, "Five Decades of Educational Assortative Mating," American Sociological Review, LVI (1991), 15-32.

[27] Reich, Robert, "Secession of the Successful," New York Times Magazine, Jan. 20 (1991).

[28] Wilson, William, J.,The Truly Disadvantaged: The Inner City, the Underclass Public Policy, Chicago, IL., University of Chicago Press, (1987). 
Figure 1

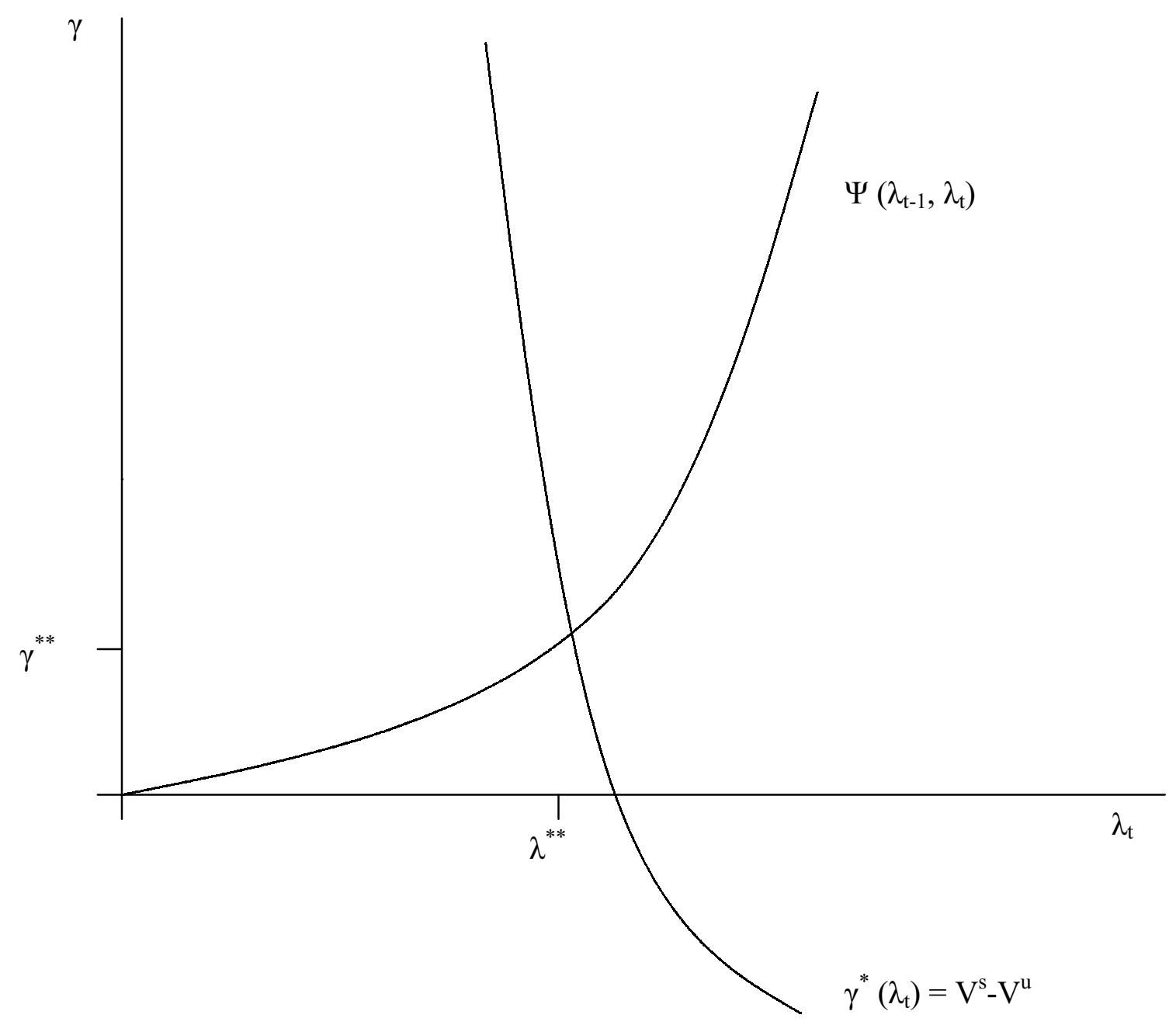


Figure 2

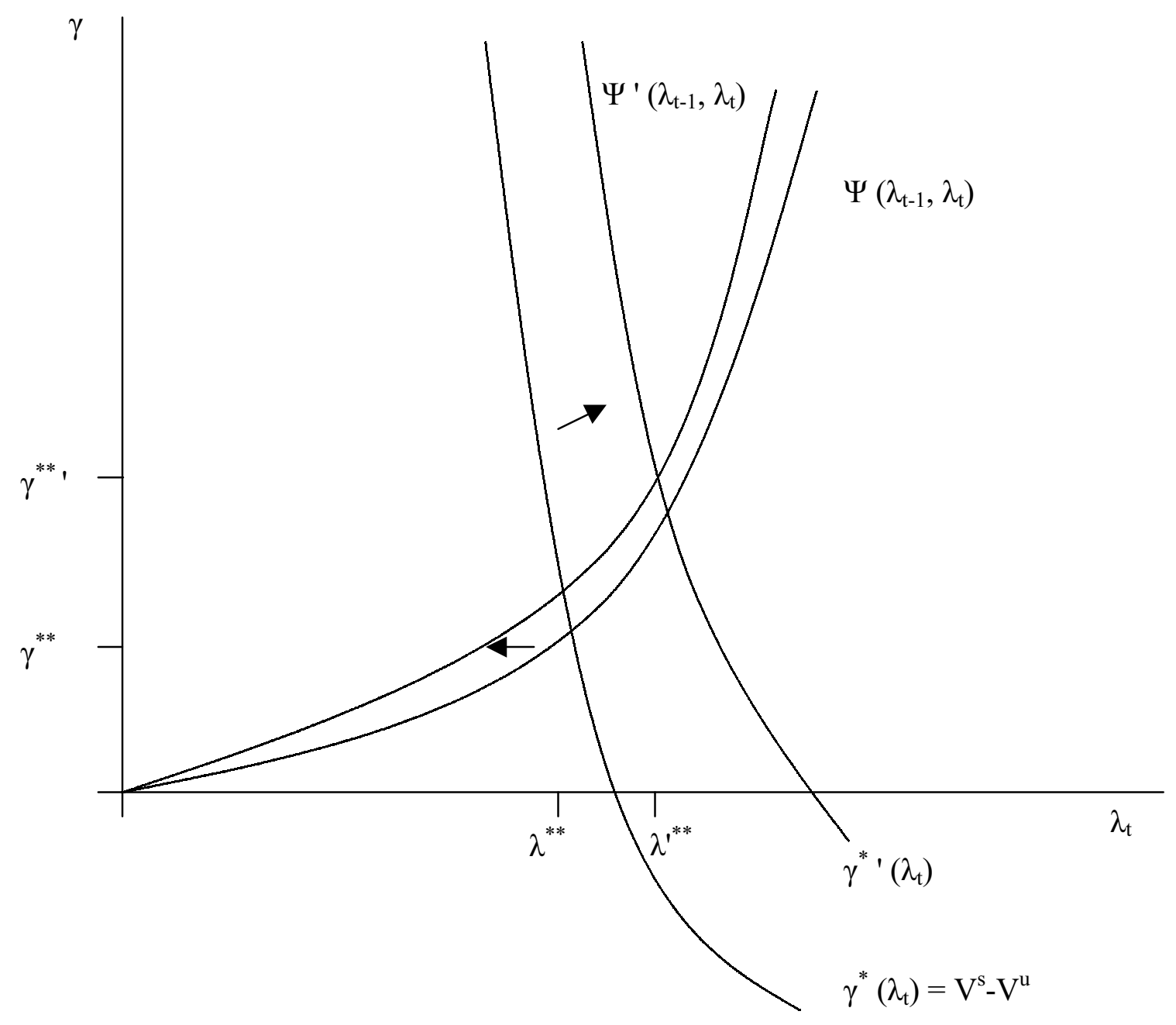

